\title{
Factors Influencing Waiting Time as Key of Patient Satisfaction in the Emergency Department in King Fahd Armed Forces Hospital, Saudi Arabia
}

\author{
Omar Zayyan Alsharqi ${ }^{1}$, Mohammed AlBarakati², Mai AlBarakati², AbdulAziz AlQamdi ${ }^{2}$, Hussein Mohammad \\ Al-Borie ${ }^{1}$, Ala'Eddin Mohammad Khalaf Ahmad ${ }^{1}$ \\ ${ }^{1}$ Faculty of Economics and Administration, King Abdul-Aziz University, Jeddah, Saudi Arabia \\ ${ }^{2}$ King Fahd Armed Forces Hospital, Jeddah, Saudi Arabia \\ Correspondence: Ala'Eddin Mohammad Khalaf Ahmad, Faculty of Economics and Administration, King \\ AbdulAziz University, Saudi Arabia. Tel: 966-56-852-7444, E-mail: amahmed1@kau.edu.sa or \\ aladdin.a.h@hotmail.com
}

Received: March 2, 2017

Accepted: April 12, 2017

Online Published: April 27, 2017

doi:10.5539/ijbm.v12n5p79

URL: https://doi.org/10.5539/ijbm.v12n5p79

\begin{abstract}
The current research investigated the factors influencing the waiting time in the emergency department (ED) in King Fahd Armed Forces Hospital in Jeddah city, Saudi Arabia. We have decided to evaluate the impact of multiple factors in the waiting time in the ED. These factors are derived from three main variables. The independent variables include the organizational, management and staffing factors, whereas the dependent variable is represented by the waiting time. The method used to collect primary data was quantitative, through a research questionnaire, which was administered in the ED of King Fahd Armed Forces Hospital. A purposive sampling strategy was used to choose the participants in this research. In total, approximately 130,000 patients per year, these patients include the adult population, paediatrics, obstetrics and gynaecology who participated in this study. Using the sample size table, the researcher distributed 384 research questionnaires. The research retrieved 308 valid questionnaires, which was a rate of $80.2 \%$. The results confirm significant influence of the organizational, management and staffing factors in the ED waiting time. Furthermore, the results also show various possibilities for future approaches to improve the waiting time. In this research, we concluded that these factors affect the waiting time in ED either in a positive or negative way, and we should take action to correct or improve the service provided to the patient visiting the ED. We recommend that a clear policy should be implemented regarding the availability of the wheelchairs, finding a direct channel with the medical administration office and the hospital administration regarding the time delay in speciality physicians to evaluate the ED patient. Regarding the difficulty in finding a bed in the ED, we recommend that the ED administration should maintain close monitoring, writing daily reports to the medical administration regarding any patient admitted in the ED under the care of the medical department to ensure a fast response in solving this problem.
\end{abstract}

Keywords: patient waiting times, ER, Saudi Arabia

\section{Introduction}

Reducing the time people spend in the ED in King Fahd Armed Forces Hospital in Jeddah (KFAFH) is a complex issue of health systems. It is not possible to solve the problem by looking at the hospital ED alone. Prompt emergency care requires making improvements across the entire system, from providing patients with information on alternative options where they can receive immediate, unplanned care, to offering timely discharge from the ED to a hospital bed, to home or to other appropriate care settings. For many individuals, the emergency room or department represents the "front door" to the healthcare system. We know that the public expects more timely access, shorter wait times and better communication and information regarding ED wait times. The length of time patients wait to see a provider in the ED is an important driver of patient satisfaction. Additionally, studies suggest that patients prefer to be provided with information and updates regarding their progress during the ED visit. In response, many EDs have begun communicating estimated wait times to the general public as part of their marketing strategy, using such methods as billboards, websites, and smartphone applications. Others have taken the decision to publicise wait times as an attempt to manage arrivals among 
multiple EDs within a given geographic area. A number of products, marketing companies, and computer applications have surfaced to assist in determining and displaying ED wait times, but their relative effectiveness, safety, and integrity remain a topic of much debate. There is a dearth of information in the literature exploring the practice of publishing ED wait times, and no universal definition of wait time or method of measurement currently exists. Whether publication of ED wait times has a positive or negative effect on various aspects of patient care and ED operations has engendered significant interest and concern within the emergency medicine community. The success of any medical institute starts from the door of the ED, and the success of the ED starts from the time you enter the front door till you leave the ED, either to your home or to the admission ward. Prolonged time waiting in the ED in an attempt to be told the decision of the practitioner - or even to be assessed - is a critical matter that has started to arise all over the world in the last few years, with crises from time to time starting to be documented everywhere. In general, in this research we are trying to answer the question concerning what are the main influencing factors that are affecting the waiting time in the ED, either positively or negatively, in visiting the ED in KFAFH. Digging more in-depth of the question of this research, we are trying to find more detailed answers for the following questions:

- Is the organizational factor of the ED having any influence on the waiting time of the ED?

- Is the management factor of the ED having any influence on the waiting time of the ED?

- Is the staffing factor of the ED having any influence on the waiting time of the ED?

Answers to all these questions will arise in this research as we go through the process of seeking the best modality to answer these questions to determine the factors that affect the waiting time in the ED and their impact on patient care. To achieve this aim, two objectives have been identified, which guided the investigation of the research problem.

\section{Literature Review}

This section seeks to describe the theoretical background associated to the factors influencing the waiting time in the ED. Moreover, it is intended to present some background about the different variables pertaining to the study. ED waiting time and overcrowding has become one of the central issues on the agenda of not only hospitals but also governments. One of the key problems is the lack of understanding by the medical staff of the importance and the danger and impact of the waiting time in the ED. A patient's wait time starts as soon as they walk through the doors of an emergency department and ends only when the patient is either discharged home or admitted to hospital. The causes of long waiting time are complex and often unique to each emergency department (Newfoundland \& Labrador, 2012). In EDs, time is considered an important measure of quality as this waiting time can affect the outcomes of patient situation and care. Additionally, the problem of lengthy waiting time can also indicate a poorly resourced, poorly managed and/or poorly co-ordinated department. In 2004, the National Health Service (NHS) in the UK introduced a target that no one should wait over four hours from arrival in the ED before being admitted, discharged, or transferred. This would reduce average waiting time in EDs to 75 minutes (Horwitz et al., 2010; Davis et al., 1995). It is important to differentiate between the treatment time and the waiting time as both are reflecting two different issues. The treatment time is defined as the patient's time after being seen by a decision-making clinician until leaving the Emergency Department. But the waiting time is the time from booking in to being seen by a decision-making clinician in an ED (Maison, 2006). Here we are looking to the waiting time, not the treatment time, and how it will be affected by several factors, which can either increase or decrease the time. The argument was which time is the more important regarding the evaluation of any $\mathrm{ED}$, as many authors consider the $\mathrm{ED}$ waiting time is more critical than the actual treatment time, which is reflected by the fact that once the patient is registered he will be under the supervision and care of the $\mathrm{ED}$, regardless of whether he or she was delayed in attempting to register, which may cause misinterpretation of the real situation of the patient, leading to serious complications. The treatment time on the other side may be delayed but the patient is already under the care of a specialized physician who can handle any serious situations that may arise at any time during the management of the patient. Sayah (2014) conducted pre- and post-intervention analysis to assess the impact of a process improvement project at the Cambridge Hospital ED. In the course of a process which was both comprehensive and collaborative, they reengineered the emergency patient experience from arrival to departure. They found that the ED operational changes have had a significant positive impact on all measured metrics, including the ambulance diversion that decreased from a mean of 148 hours per quarter before amendments which were introduced in July 2006, to 0 hours following April 2007. ED total length of stay decreased from a mean of 204 minutes before the changes to 132 minutes. ED patient volume grew by $11 \%$, from a mean of 7221 patients per quarter to 8044 patients per quarter. Compliance with specific ED quality core measures improved from a mean of $71 \%$ to $97 \%$. The mean 
rate of ED patients who left without being seen (LWBS) dropped from $4.1 \%$ to $0.9 \%$. Improving ED operational efficiency allowed them to accommodate increasing volume while improving the quality of care and satisfaction of ED patients with minimal additional resources, space, or staffing. Stephen's (2008) report presents the most up-to-date (2006) nationally representative data on visits to hospital EDs in the United States. Statistics are given for specific hospital, patient, and visit characteristics. Data were collected from the 2006 National Hospital Ambulatory Medical Care Survey (NHAMCS), the longest continuously running nationally representative hospital ED utilization survey. The NHAMCS collects data on visits to emergency and outpatient departments of non-federal, short-stay and general hospitals in the United States. Sample data are weighted to produce annual national estimates. This study found that there were 119.2 million visits to hospital EDs, or 40.5 visits per 100 persons, continuing a long-term increase in both measures. The rate of visits per 100 persons was 36.1 for white persons, 79.9 for black persons, and 35.3 for Hispanic persons. ED occupancy (the count of patients who had arrived, but were not yet discharged, transferred, or admitted) varied from 19,000 patients at 6 a.m. to 58,000 at 7 p.m. on an average day nationally. Though overall ED visits increased, the number of visits which were seen as emergency or urgent (15.9 million) did not change significantly from 2005, nor did the number of patients arriving by ambulance (18.4 million). In 3.6 percent of visits, the patient had been seen in the same ED within the previous 72 hours. Median time to see a clinician was 31 minutes. Of all ED visits, 35.6 percent were for an injury. Patients received computerized tomography or magnetic resonance imaging at 12.1 percent of visits, had blood drawn at 38.8 percent, had an intravenous line started at 24.0 percent, had an X-ray performed at 34.9 percent, and had an electrocardiogram done at 17.1 percent. Patients were admitted to the hospital at 12.8 percent of ED visits in 2006. The ED was the portal of admission for 50.2 percent of all non-obstetric admissions in the United States in 2006, an increase from 36.0 percent in 1996. Patients were admitted to an intensive care unit at 1.9 percent of visits. Almulhim (2015) identified the key factors influencing the average patient waiting time from bed check-in to discharge as a key performance indicator (KPI) of the emergency department at National Guard Health Affairs, Dammam Hospital. The author used a cross-sectional study using a questionnaire that consisted of 29 items developed to highlight the main factors that have an impact on patients' waiting time in the ED. Using convenience sampling, all emergency room caregiver staff at Dammam NGHA hospital were targeted to participate in this study. Between February and March 2013, 110 participants completed the survey with a response rate of $87.3 \%$. They found that mean waiting time in the emergency department was 123.82 minutes after bed check-in. As a result, their findings show that factors including participant's level of education, working schedule, years of experience as well as health information system accessibility, had a statistically significant but weak relationship with the average waiting time after bed check-in $(\mathrm{p}<0.05)$ with the exception of work field, which showed a medium positive relationship $(\mathrm{r}=0.302)$. The participants' working schedule and health information system accessibility were the most significant variables that influenced the patients' average waiting time after bed check-in in the emergency room. And they concluded that this study has identified five factors that may influence patient waiting time after bed check-in in the emergency room at NGHA Dammam Hospital: participant's work field, level of education, working schedule, years of experience and health information system accessibility. Stakeholders need to act to put in place proper solutions which may lead to better delivery of patient care in the emergency room. Further studies should also focus on gathering the opinions of staff and patients to ensure high quality of services in the emergency room. Bukhari (2014) tried to measure the quality of provided services to patients in terms of measuring the total length of stay time (LOS) in ED and its influencing factors. It is a prospective study aiming to estimate the average time patients spend in ED of Alnoor Hospital during the month of January (2013). In addition, it inspects factors influencing the LOS. Using the methodology of the questionnaire which was conducted and filled by the emergency team over all patients, and consisted of the following data: arrival time to ED, initial time of assessment by nurse, initial time of assessment by doctor, time of arrival to specific area, consultation time, arrival time of consulted specialty, time of laboratory investigation, time of radiological investigation, time of final disposition and time of physical disposition. They found that for the 7604 patient visits analyzed, mean ED LOS was 3.02 hour ( $\mathrm{SD}=5.03$ hour). About half of the patients spent less than 59 minutes (44\%), 32.6\% spent 1 to $3: 59$ hour, $15.2 \%$ spent 4 to $7: 59$ hour, and $8.2 \%$ of the patients spent more than 8 hours. They came up with the result that such a study will offer a chance to evaluate the recent ED performance and assist to adapt future optimization strategies to improve the quality of services provided to the patient. In summary, we notice that there are many common findings between our study and the above mentioned studies regarding the factors influencing the waiting in ED, and the overall conclusion especially that we used these studies as a backbone to our study, i.e. using the questionnaire method, depending on the influencing factors to build our study. Three hypotheses were formulated in the current research:

1. There is a positive significant relationship between organizational factors and the waiting time in the ED at KFAFH. 
2. There is a positive significant relationship between management factors and the waiting time in the ED at KFAFH.

3. There is a positive significant relationship between staffing factors and the waiting time in the ED at KFAFH.

\section{Rationale of the Research}

The research importance focuses on the determination and study of factors affecting ED waiting time being a very important issue that helps the hospital administration to properly improve patient safety and the quality of treatment provided to the patients in King Fahd Armed Forces Hospital in Jeddah. This research will make a positive contribution in the direction of antecedents of factors influencing on waiting time, which leads to patient care. Therefore, the present study attempts to fill a gap in the subject of antecedents of waiting time in King Fahd Armed Forces Hospital in Jeddah.

\section{Research Aim and Objectives}

Based on the above section highlighting the ED waiting time problem in KFAFH, the research objectives of this research are:

1. To identify the factors that influence the waiting time in the ED in KFAFH.

2. To study the impact of these factors (organizational, management, and staffing) on the waiting time in the ED at KFAFH.

\section{Research Methodology}

\subsection{Type of Research}

This research is a descriptive analytical study using a cross-sectional survey in which many random ED patients of KFAFH are included. It is a single cross-sectional design in which the collection of information from the research population and respondents are performed once only.

\subsection{The Research Population and Sample}

The research population consists of the ED in KFAFH. The population in this research is defined as all the patients visiting the ED in KFAFH. The average number of patients visiting the ED in KFAFH are 130,000 per year. These patients include the adult population, paediatrics, obstetrics and gynaecology. The research respondents consist of 384 patients, all of which the researcher took as a purposive research sample. The research retrieved 308 valid questionnaires, which amounted to $80.2 \%$.

\section{Research Model and Hypotheses}

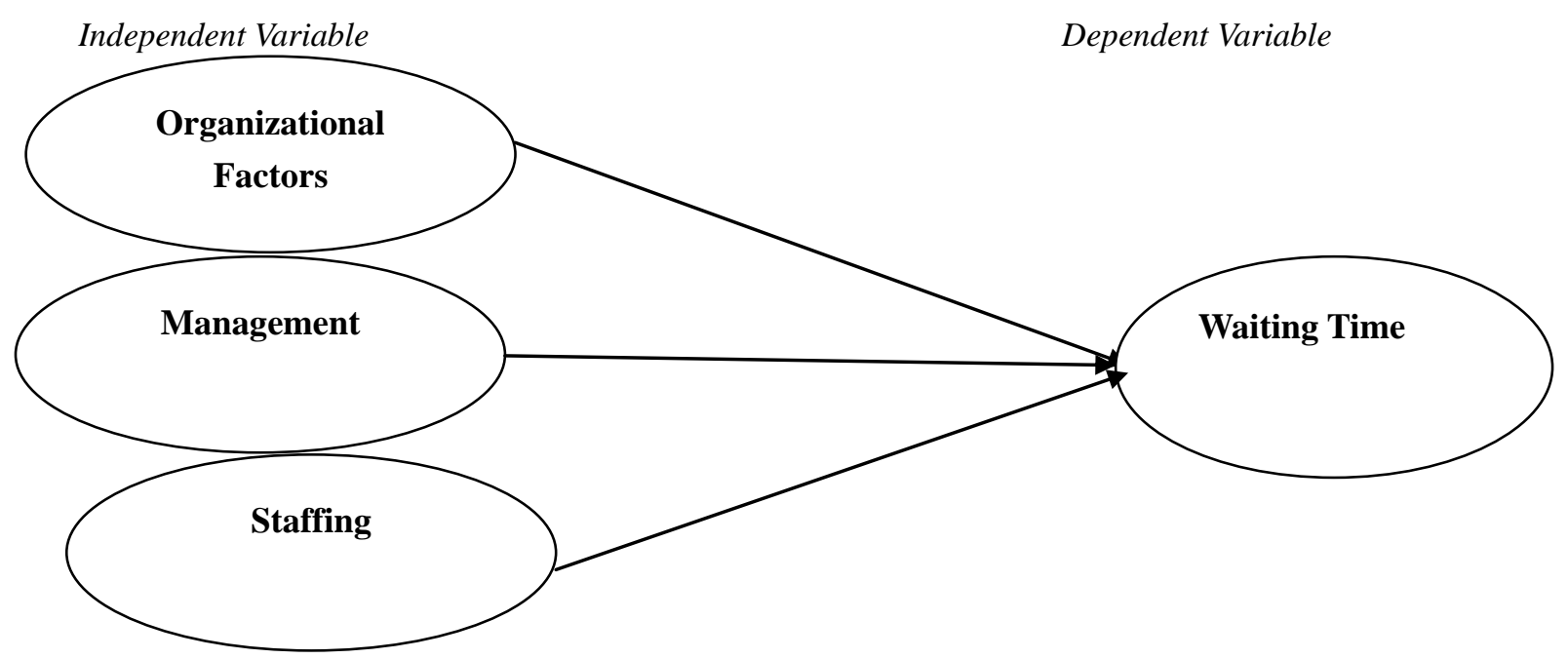

Figure 1. Research model

\subsection{Research Hypotheses}

1- There is a significant relationship between organization dimension and waiting time in ED at KFAFH.

2- There is a significant relationship between staff dimension and waiting time in ED at KFAFH.

3- There is a significant relationship between administration dimension and waiting time in ED at KFAFH. 


\section{Data Analysis and Results Discussion}

\subsection{Demographic Data Results}

Table 1. Frequency and percentage for demographic information

\begin{tabular}{|c|c|c|c|}
\hline & & Frequency & Percentage \\
\hline \multirow{3}{*}{ Gender } & Female & 162 & 52.6 \\
\hline & Male & 146 & 47.4 \\
\hline & Total & 308 & 100.0 \\
\hline \multirow{4}{*}{ Nationality } & Saudi & 302 & 98.1 \\
\hline & Non-Saudi & 6 & 1.9 \\
\hline & Total & 308 & 100.0 \\
\hline & Under 30 years & 126 & 40.9 \\
\hline \multirow{4}{*}{ Age } & $30-40$ years & 85 & 27.6 \\
\hline & $41-50$ years & 40 & 13.0 \\
\hline & $51-60$ years & 30 & 9.7 \\
\hline & More than 60 years & 26 & 8.4 \\
\hline \multirow{7}{*}{ Education Level } & Total & 308 & 100.0 \\
\hline & Less than secondary & 80 & 26.0 \\
\hline & Secondary & 101 & 32.8 \\
\hline & University degree & 112 & 36.4 \\
\hline & Higher education & 15 & 4.9 \\
\hline & Total & 308 & 100.0 \\
\hline & Rapidity in service delivery & 195 & 63.3 \\
\hline \multirow[t]{2}{*}{ Influencing your satisfaction } & Quality of service & 113 & 36.7 \\
\hline & Total & 308 & 100.0 \\
\hline \multirow{3}{*}{ Are you comfortable } & Comfortable & 52 & 16.9 \\
\hline & Uncomfortable & 256 & 83.1 \\
\hline & Total & 308 & 100.0 \\
\hline
\end{tabular}

\section{Table 1 shows that:}

1. The percentage for "gender" reached (47.4\%) for male, but the percentage for female reached $(52.6 \%)$.

2. The percentage for "nationality" reached $(98.1 \%)$ for Saudi, but the percentage for Non-Saudi reached $(1.9 \%)$.

3. The highest percentage for "age" reached $(40.9 \%)$ for age category less than 30 years, but the lowest percentage reached (8.4\%) for age category more than 60 years.

4. The highest percentage for "education" reached (36.4\%) for bachelor holders, but the lowest percentage reached (4.9\%) for higher education holders.

5. The highest percentage for "influencing your satisfaction" reached (63.3\%) for rapidity in service delivery, but the lowest percentage reached $(36.7 \%)$ for quality of service.

6. The highest percentage for "are you comfortable" reached $(83.1 \%)$ for uncomfortable, but the lowest percentage was $(16.9 \%)$ for comfortable.

\subsection{Research Variables Tests (Mean, SD, Chi-Square)}

Table 2. Mean and standard deviation

\begin{tabular}{lllll}
\hline No. & Items & Mean & S.D & Chi-Square \\
\hline 1 & It was easy and accessible getting a wheelchair & 2.5097 & 1.35176 & $60.084^{\text {a }}$ \\
2 & Vital signs being taken easily & 3.4221 & 1.32764 & $67.747^{\text {a }}$ \\
3 & Lab tests in ED & 3.4773 & 1.30751 & $63.526^{\text {a }}$ \\
\hline
\end{tabular}




\begin{tabular}{lllll}
\hline 4 & X-ray tests in ED & 3.5779 & 1.25188 & $87.227^{\mathrm{a}}$ \\
5 & Service area is easy to identify & 3.2955 & 1.32640 & $34.825^{\mathrm{a}}$ \\
& Organization & 3.2565 & & \\
\hline
\end{tabular}

Table 2 shows the mean ranging from (2.50 - 3.57), with the highest mean for item (4) "X- ray tests in ED", but the lowest mean for item (1) "It was easy and accessible getting a wheelchair". The overall mean for "organizational factors" was (3.25).

Table 3. Mean and standard deviation for items and chi square test

\begin{tabular}{lllll}
\hline No. & Items & Mean & S.D & Chi-Square \\
\hline 1 & Received by paramedics & 3.4495 & 1.34306 & $43.342^{\mathrm{a}}$ \\
2 & Emergency doctor examined you in the triage area & 3.4416 & 1.30390 & $88.591^{\mathrm{b}}$ \\
3 & Emergency doctor acted professionally & 3.5292 & 1.27713 & $73.006^{\mathrm{b}}$ \\
4 & ED staff (non-medical) acting professionally, rapidly \& collecting data. & 3.5195 & 1.33712 & $73.331^{\mathrm{b}}$ \\
5 & Specialist doctor (not emergency doctor) examined you. & 3.1299 & 1.31986 & $30.734^{\mathrm{b}}$ \\
& Staff factors & 3.41 & & \\
\hline
\end{tabular}

Table 3 shows a mean range from (3.52 - 3.12), with the highest mean being for item (3) "Emergency doctor acted professionally", but the lowest mean for item (5) "Specialist doctor (not emergency doctor) examined you". The overall mean for "staff" was (3.41).

Regarding the Chi square test, the table shows that two out of five are significant; on the other hand, three out of five are insignificant.

Table 4. Mean and standard deviation for items and Chi Square Test

\begin{tabular}{lllll}
\hline No. & Items & Mean & S.D & Chi-Square \\
\hline 1 & ED registration process was easy and accessible & 3.7857 & 1.21051 & $114.305^{\mathrm{a}}$ \\
2 & Providing bed in emergency department was fast & 2.6851 & 1.40549 & $39.890^{\mathrm{a}}$ \\
& While discharging, take-home medication was dispensed in an & & & $40.864^{\mathrm{a}}$ \\
3 & $\begin{array}{l}\text { appropriate timescale } \\
4\end{array}$ & 2.9935 & 1.28634 & $26.188^{\mathrm{a}}$ \\
5 & Your demands have been heard well & 3.1429 & 1.33326 & $55.409^{\mathrm{a}}$ \\
& Discharge process from ED was done in an appropriate timescale & 3.0519 & 1.24932 & \\
\hline
\end{tabular}

Table 4 shows a mean range from (2.68-3.78), with the highest mean being for item (1) "emergency department registration process was easy and accessible", and the lowest mean for item (2) "Providing bed in emergency department was fast". The overall mean for "administration" was (3.13).

Regarding the Chi square test, the table shows that all of the workplace items are significant.

\subsection{Research Variables}

\section{a- Organization}

Table 5. Organizational dimension

\begin{tabular}{llllll}
\hline & Org 1 & Org 2 & Org 3 & Org 4 & Org 5 \\
\hline Chi-Square & $60.084^{\mathrm{a}}$ & $67.747^{\mathrm{a}}$ & $63.526^{\mathrm{a}}$ & $87.227^{\mathrm{a}}$ & $34.825^{\mathrm{a}}$ \\
df & 4 & 4 & 4 & 4 & 4 \\
Asymp. Sig. & .000 & .000 & .000 & .000 & .000
\end{tabular}

a. 0 cells $(0.0 \%)$ have expected frequencies less than 5. The minimum expected cell frequency is 61.6.

Regarding the Chi square test the table shows that all organization dimension variables are significant. 


\section{b- Staff}

Table 6. Staff Dimension

\begin{tabular}{llllll}
\hline & Staff 1 & Staff 2 & Staff 3 & Staff 4 & Staff 5 \\
\hline Chi-Square & $43.342^{\mathrm{a}}$ & $88.591^{\mathrm{b}}$ & $73.006^{\mathrm{b}}$ & $73.331^{\mathrm{b}}$ & $30.734^{\mathrm{b}}$ \\
Df & 4 & 4 & 4 & 4 & 4 \\
Asymp. Sig. & .000 & .000 & .000 & .000 & .000 \\
\hline
\end{tabular}

a. 0 cells $(0.0 \%)$ have expected frequencies less than 5 . The minimum expected cell frequency is 61.4.

b. 0 cells $(0.0 \%)$ have expected frequencies less than 5. The minimum expected cell frequency is 61.6.

Regarding the Chi square test the table shows that all of the staff dimension variables are significant.

\section{c- Administration}

Table 7. Administration dimension

\begin{tabular}{llllll}
\hline & Admin 1 & Admin 2 & Admin 3 & Admin 4 & Admin 5 \\
\hline Chi-Square & $114.305^{\mathrm{a}}$ & $39.890^{\mathrm{a}}$ & $40.864^{\mathrm{a}}$ & $26.188^{\mathrm{a}}$ & $55.409^{\mathrm{a}}$ \\
Df & 4 & 4 & 4 & 4 & 4 \\
Asymp. Sig. & .000 & .000 & .000 & .000 & .000 \\
\hline
\end{tabular}

a. 0 cells $(0.0 \%)$ have expected frequencies less than 5 . The minimum expected cell frequency is 61.6 .

Regarding the Chi square test the table shows that all of the administration variables items are significant.

\subsection{Research Hypotheses Tests}

1- There is a significant positive relationship between organization dimension and waiting time in ED at KFAFH.

2- There is a significant positive relationship between staff dimension and waiting time in ED at KFAFH.

3- There is a significant positive relationship between administration dimension and waiting time in ED at KFAFH.

Table 8. Chi-Square test (organization, staff, and administration)

\begin{tabular}{llll}
\hline & Org & Staff & Admin \\
\hline Chi-Square & $82.273^{\mathrm{a}}$ & $118.136^{\mathrm{a}}$ & $88.883^{\mathrm{b}}$ \\
Df & 20 & 20 & 19 \\
Asymp. Sig. & .000 & .000 & .000 \\
\hline
\end{tabular}

a. 0 cells $(0.0 \%)$ have expected frequencies less than 5 . The minimum expected cell frequency is 14.7 .

b. 0 cells $(0.0 \%)$ have expected frequencies less than 5 . The minimum expected cell frequency is 15.4 .

All of the three research hypotheses were accepted.

\subsection{Research Discussion}

This section deals with a brief interpretation of the data which has been analyzed through the system and displayed on the tables:

What has been discovered, and was unsurprising, is that the female to male ratio was almost the same, with the females standing at $53 \%$ and the males at $47 \%$. But when it comes to nationalities, as this is a military hospital dealing with mainly military personnel, most of them were Saudi, so the ratio differed by a margin, as expected, with $98 \%$ for Saudis and only $2 \%$ for non-Saudis, who came from the personnel working in the hospital, either from the medical staff or from the supporting services. Most of the patients were under 30 years old, being $40 \%$ of the total number of patients, followed by the age of 30 to 40 years, with a percentage of $27 \%$. Of course, when looking at the analysis of the comfort of patients when it came to a delay in the time of management, the results were logical, as $83 \%$ were uncomfortable waiting more time in ED, but the shocking results came from the factor that people preferred, picking rapidity of service over quality of service, with $63 \%$ stating that they are looking for rapidity rather than quality. The results could be reflected by the educational level, which was almost 
$30 \%$ with secondary education, and $26 \%$ less than secondary education, or could be caused by some other reason as the ED is usually overcrowded; some people just need the management and will leave instantly regardless of the quality of treatment provided to them. Looking into the organizational factors affecting waiting time and from the questionnaire, which was distributed to the patients in the ED analyzing the mean and the standard deviation, we found out that the highest mean goes to the X-ray test in the ED, and the lowest goes to the easy accessibility of wheelchairs. Moving onto the staff factors affecting the waiting time on studying the mean and standard deviation for them and the Chi square test, we found that the highest mean goes to emergency doctors acting professionally and the lowest goes to the specialist doctors not examining the patients on time. Following the Chi square we have found that two of the five factors regarding the staff that affected the waiting time are significant, while the other three were not. Following the administrative factors affecting the waiting time and looking after the mean and standard deviation with the Chi square test, we found that the highest mean was mainly concerned with the ED registration process and its easiness and accessibility, with the lowest mean going to finding an ED bed instantly when the patient arrives at the ED, and the chi square shows that the administrative factors and the workplace are all significant. In brief, we have found that all factors affecting the ED waiting time are either organizational, administrative or staffing. All came as significant, but what was interesting about the study is that the three research hypotheses that have been discussed previously were all accepted.

\section{Conclusion and Recommendation}

\subsection{Research Conclusion}

Collecting and analyzing all the data has been trying to prove or disprove the three hypotheses, which are finding if there is any relation between the organization dimension and the waiting time in the ED, between the staff dimension and the waiting time in the $\mathrm{ED}$, and between the administration dimension and the waiting time in the ED, which all became significant by analysis. Now, it is time to conclude all the data and the findings in the research. The conclusions are:

1. All three factors (organizational, staff and administrative) have an impact either positively or negatively on the waiting time in the ED.

2. Most of the patients agreed that the accessibility to get a wheelchair in the ED was difficult, and this belongs to the organizational dimension, causing the patients to be delayed when entering the ED in searching for a wheelchair.

3. The organizational plan in the ED in King Fahd Armed Forces Hospital, Jeddah shows the other criteria for the organizational factors, which are the triage area, accessibility, rapidity of service, laboratory test and X-ray test and identifying all areas in the ED was easy for the patients, and did not cause delay in their management.

4. Regarding the staff factor and its influence on waiting time in ED, we have noticed from the responses that the specialist doctor did not see them at the proper time and they are not satisfied with their management. Otherwise, the responses regarding the ED staff acting professionally and rapidly, examining them properly in the triage area, and whether the patient was received by paramedics from the entrance area, were always positive.

5. Regarding administration factors influencing the waiting time in the ED, most of the patients agreed that the registration process was easy and accessible, and the discharge process and finding a bed was not satisfying for them; regarding any complaint and direct discharge in an appropriate time was satisfying for them. As a final conclusion, most of the presented factors, organizational, staffing and administrative, had a significant positive impact on the ED waiting time. But, we would still like to further improve them to achieve even better results. Therefore, all the factors will be discussed to find flaws or areas needing improvement.

\subsection{Research Recommendations}

Due to the majority of the patients complaining that they could not get easy access to a wheelchair, we recommend that it is better to have a clear policy regarding the availability and distribution of the wheelchairs in the ED area to ensure that there will be no loss of wheelchairs, as most patients will use them and they don't have to return them. We could use the patient's medical card in return for the wheelchair. As mentioned before, the triage area is the most crowded area in ED. Although it has been recorded as an easily accessible area, still it is crowded. We do believe a better redistribution of the area and the pathways will create a proper healthy environment for the patients in the ED. Looking into the professionalism of the emergency physicians, this was acceptable, but there was a major issue with speciality physicians delaying the waiting time of the ED patients, which definitely is a risk not only for the time, but also for the safety, of the patients. We recommend that the hospital administration, including the medical administration office, should interfere in this matter by instructing 
and reminding all the involved medical departments in the ED that patient safety is the priority of the hospital, and any delay in the management will adversely affect the physician's evaluation and may put him/her under direct investigation. Another major issue in most of the hospitals around the world is finding a bed in the ED, which we also have. Our ED is equipped with 67 beds, all occupied with either medical or surgical inpatients, due to the fact that we don't have beds in the wards. We cannot blame any factors from the three factors influencing the waiting in ED (organization, staff, administrative) but the role of the ED administration is to keep tracking and monitoring, writing daily reports to the medical administration about the situation in the ED, facilitating any possible way to speed up the process of investigation and treatment of inpatients in the ED, to avoid a situation that may affect not only the ED but the whole hospital in the case of a major disaster situation, crisis, or multiple trauma, especially in the critical area of the ED, where whatever happens to affect patient safety will not only be reflected in one department, but throughout the whole institute, representing one sector in the health organization in the Kingdom of Saudi Arabia.

\section{References}

Alyasin, A., \& Douglas, C. (2014). Reasons for Non-Urgent Presentations to the Emergency Department in Saudi Arabia. International Emergency Nursing, 22, 220-225. https://doi.org/10.1016/j.ienj.2014.03.001

American College of Emergency Physicians. (2012). Publishing Wait Times for Emergency Department Care-an Information Paper, June 2012.

Assad. (2014). Minimizing ED Waiting Times and Improving Patient Flow and Experience of Care. Emergency Medicine International.

Bhuiya, E. (2012). Wait Time for Treatment in Hospital Emergency Departments: 2009, NCHS Data Brief.

Chan, T., Killeen, J., Kelly, D., \& Guss, D. A. (2005). Impact of rapid entry and accelerated care at triage on reducing emergency department patient wait times, lengths of stay, and rate of left without being seen. Annals of Emergency Medicine, 46(6), 491-497. https://doi.org/10.1016/j.annemergmed.2005.06.013

Davis, B. et al. (1995). Factors Affecting ED Length-of-Stay in Surgical Critical Care Patients. American Journal of Emergency Medicine, 13, 495-500. https://doi.org/10.1016/0735-6757(95)90155-8

Elkum, N. B. (2011). Canadian Emergency Department Triage and Acuity Scale: Implementation in a Tertiary Care Center in Saudi Arabia. Boston Medical Center Emergency Medicine, 11, 3.

Georgievskiy, I., Georgievskaya, Z., \& Pinney, W. (2008). Using computer simulation modeling to reduce waiting times in emergency. 1-18.

Horwitz, L. I. (2010). US Emergency Department Performance on Wait Time and Length of Visit. Annals of Emergency Medicine, 55, 133-141. https://doi.org/10.1016/j.annemergmed.2009.07.023

Johnson, K. D., \& Winkelman, C. (2011). The effect of emergency department crowding on patient outcomes: a literature review. Advanced Emergency Nursing Journal, 33(1), 39-54. https://doi.org/10.1097/TME.0b013e318207e86a

Krall, S. P. (2014). Hospital Factors Impact Variation in Emergency Department Length of Stay More than Physician Factors. Western Journal of Emergency Medicine, 15, 158-164. https://doi.org/10.5811/westjem.2013.12.6860

Locker, T. (2005). Targets and Moving Goal Posts: Changes in Waiting Times in a UK Emergency Department. Emergency Medicine Journal, 22, 710-714. https://doi.org/10.1136/emj.2004.019042

MacHugh, M. (2011). Improving patient flow and reducing emergency department crowding: A guide for hospitals.

McKinsey Quarterly. (2014). A hospital-wide strategy for fixing emergency-department overcrowding.

Ontario Hospital. (2011). Leading practice in Emergency Department.

Patel, P., \& Vinson, D. (2005). Team assignment system: expediting emergency department care. Annals of Emergency Medicine, 46(6), 499-506. https://doi.org/10.1016/j.annemergmed.2005.06.012

Tashkandy, M. A. (2008). Reasons for Delay in Inpatient Admission at an Emergency Department. Journal of Ayub Medical College Abbottabad, 20, 38-42.

Travers, J., \& Lee, F. (2006). Avoiding prolonged waiting time during busy periods in the emergency department: is there a role for the senior emergency physician in triage? European Journal of Emergency Medicine, 13(6), 342-348. 


\section{Appendix: A}

Put $x$ in your right choice:

Age:
$\square$ Less than 30
$\square 30-40$
$\square 41-50$
$\square 51-60$
$\square$ more than 60

Gender:

$\square$ Female

$\square$ Male

Nationality:

$\square$ Saudi

$\square$ Non-Saudi

Educational Level

$\square$ Less than secondary

$\square$ Secondary

$\square$ University

$\square$ High Qualified

What is the factor, which most affects you in the Emergency Department, in your opinion?

$\square$ Rapidity in Service Delivery

$\square$ Quality in Service

In case of a long-term waiting period in the Emergency Department, to what extent do you feel comfortable?

$\square$ Comfortable

$\square$ Uncomfortable

Section Two: You are kindly asked to mark $(\mathrm{X})$ in the appropriate box that expresses your viewpoint in the following:

\begin{tabular}{|c|c|c|c|c|c|}
\hline Degree of Agreement & $\begin{array}{l}\text { Strongly } \\
\text { disagree }\end{array}$ & Disagree & Neutral & Agree & $\begin{array}{l}\text { Strongly } \\
\text { agree }\end{array}$ \\
\hline & 1 & 2 & 3 & 4 & 5 \\
\hline
\end{tabular}

\begin{tabular}{|l|l|l|l|l|}
\hline \multicolumn{2}{|l|}{ The Organizational factors that affect waiting period } & & & \\
\hline It was easy and accessible getting a wheelchair & & & & \\
\hline Vital signs were taken easily & & & & \\
\hline Lab tests in Emergency Department & & & & \\
\hline X-ray tests in Emergency Department & & & & \\
\hline Service area is easy to identify & & & & \\
\hline Emergency Department staff Factors that affect the waiting period & & & & \\
\hline Received by paramedics & & & & \\
\hline Emergency doctor examined you in the triage area & & & & \\
\hline Emergency doctor acted professionally & & & & \\
\hline $\begin{array}{l}\text { Emergency Department staff (non-medical) acting professionally, rapidly \& collecting } \\
\text { data. }\end{array}$ & & & & \\
\hline Specialist doctor (not emergency doctor) examined you. & & & \\
\hline Emergency Department Administration Factors that affect the waiting period & & & & \\
\hline Emergency Department registration process was easy and accessible & & & \\
\hline Providing a bed in Emergency Department was fast & & & \\
\hline While discharging, take-home medication was dispensed in an appropriate timescale & & & & \\
\hline Your demands have been heard well & & & & \\
\hline Discharge process from Emergency Department was done in an appropriate timescale & & & & \\
\hline
\end{tabular}

\section{Copyrights}

Copyright for this article is retained by the author(s), with first publication rights granted to the journal.

This is an open-access article distributed under the terms and conditions of the Creative Commons Attribution license (http://creativecommons.org/licenses/by/4.0/). 